\title{
The joint contribution of maternal history of early adversity and adulthood depression to socioeconomic status and potential relevance for offspring development
}

\author{
Andrée-Anne Bouvette-Turcot ${ }^{\mathrm{a}, \mathrm{b}, \mathrm{c}, \mathrm{d}}$, Eva Unternaehrer ${ }^{\mathrm{a}, \mathrm{b}, \mathrm{c}}$, Hélène Gaudreau ${ }^{\mathrm{a}, \mathrm{b}, \mathrm{c}}$, \\ John E. Lydon ${ }^{\mathrm{e}}$, Meir Steiner ${ }^{\mathrm{f}, \mathrm{g}}$, Michael J. Meaney ${ }^{\mathrm{a}, \mathrm{b}, \mathrm{c}, \mathrm{h}, *}$, on behalf of the MAVAN Research \\ Team \\ a Sackler Program for Epigenetics \& Psychobiology at McGill University, Montreal, Canada \\ ${ }^{\mathrm{b}}$ Ludmer Centre for Neuroinformatics \& Mental Health, Montreal, Canada \\ c Douglas Mental Health University Institute of McGill University, Montreal, Canada \\ ${ }^{\mathrm{d}}$ Department of Psychology, University of Montreal, Montreal, Canada \\ e Department of Psychology, Mcgill University, Montreal, Canada \\ ${ }^{\mathrm{f}}$ Department of Psychiatry and Behavioral Neurosciences, McMaster University, Hamilton, Canada \\ ${ }^{g}$ Women's Health Concerns Clinic, St. Joseph's Healthcare, Hamilton, Canada \\ ${ }^{\mathrm{h}}$ Singapore Institute for Clinical Sciences, Singapore
}

Keywords:

Maternal adversity

Maternal depression

Socioeconomic status

Symptoms behavioral

\begin{abstract}
A B S T R A C T
Background: We examined the interactive effects of maternal childhood adversity and later adulthood depression on subsequent socioeconomic status (SES).

Methods: Our community sample ranged from 230 to 243 mothers (across measures) drawn from a prospective, longitudinal cohort study. Maternal childhood adversity scores were derived using an integrated measure derived from the Childhood Trauma Questionnaire (CTQ) and the Parental Bonding Index (PBI). Maternal depression was measured in the prenatal period with the Center for Epidemiologic Studies Depression Scale (CES-D). SES measures included maternal highest level of education and family income as obtained prenatally.

Results: The analyses yielded significant interaction effects between maternal childhood adversity and prenatal depression that predicted income, prenatally. Women who reported higher levels of childhood adversity combined with higher levels of self-reported depressive symptoms were significantly more likely to live in low SES environments. Results also showed that level of education was predicted by childhood adversity independent of maternal symptoms of depression.

Conclusion: The results suggest that SES is influenced by a life course pathway that begins in childhood and includes adversity-related mental health outcomes. Since child health and development is influenced by both maternal mental health and SES, this pathway may also contribute to the intergenerational transmission of the risk for psychopathology in the offspring. The results also emphasize the importance of studying potential precursors of low SES, a well-documented environmental risk factor for poor developmental outcomes in the offspring.
\end{abstract}

\section{1. . Introduction}

Childhood adversity associates with increased risk for later adjustment problems. Childhood maltreatment, for example, predicts a greater risk for depression and anxiety disorders [e.g.,

* Correspondence to: Douglas Mental Health University Institute, McGill University, 6875 boul. LaSalle, Montréal, Québec, Canada H4H 1R3.

E-mail address: michael.meaney@mcgill.ca (M.J. Meaney).
(Fergusson et al., 2008; Heim and Nemeroff, 2001; Lansford et al., 2002; Thornberry et al., 2001; Trickett et al., 2001; Widom et al., 2007)]. The link between childhood adversity and depression was confirmed in a prospective cohort study (Widom et al., 2007). Childhood trauma also influences the severity and chronicity of depression as well as treatment outcomes (Zlotnick et al., 1997; Zlotnick et al., 2001; Brown and Moran, 1994; Tanskanen et al., 2004). Likewise, adverse familial conditions such as recurring emotional neglect, family conflict, and conditions of harsh 
discipline increase the risk for affective illness (Van Brakel et al., 2006; Shanahan et al., 2008). Hill et al. Hill et al., (2001) also found that low maternal care and childhood sexual abuse each contribute independently to the risk of developing depressive symptoms in adult women, suggesting distinct influences of trauma and parenting [also see (Parker et al., 1979)]. Thus, maladaptive parentchild relationships as well as trauma increase the risk of mental disorders and related endophenotypes in later life (Hane and Fox, 2006). These findings indicate that child development is influenced by parental care across a wide parent - chid interactions range that is not solely attributable to more extreme forms of maltreatment [e.g., (Hane and Fox, 2006)].

Maternal childhood adversity also predicts the risk for mood disorders in the offspring, such that the effects of adversity are seemingly transmitted to the next generation [e.g., (Plant et al., 2013)]. For example, increased maternal childhood adversity associates with child developmental outcomes such as heightened levels of negative emotionality (Bouvette-Turcot et al., 2015), an increased risk for maltreatment (Berlin et al., 2011), and enhanced vulnerability to psychopathology (Collishaw et al., 2007). While these findings suggest an intergenerational transmission, the pathways linking maternal childhood adversity to child development are not yet fully clarified. As noted above, individuals with a history of childhood adversity show a greater risk for depression (Bifulco et al., 2002; Kessler, 2006; Nanni et al., 2012; Kessler, 1997). Maternal depression is a risk factor for child psychopathology (Caspi et al., 2003; Goodman et al., 2011; Weissman et al., 2005; Weissman et al., 2006) and successful treatment of depression in the mother diminishes the risk for psychopathology in the offspring (Wickramaratne et al., 2011). These findings suggest that the mental health of the mother influences the quality of care afforded the offspring, which might then directly influence child development (Brown and Whiteside, 2008; Cicchetti and Toth, 1995; Rubin et al., 1991; Galambos et al., 2003; Hale et al., 2006; Lieb et al., 2000). However, mediational analyses suggest that the quality of maternal care does not fully account for the effects of maternal depression on developmental outcomes [e.g., (Burt et al., ; Kiernan and Huerta, 2008)]. These findings suggest that maternal adversity and associated mental health status may influence additional, important features of the child's environment beyond that of parental care.

Socio-economic status (SES) is a well-established predictor of health outcomes [e.g., (Backlund et al., 1996; Isaacs and Schroeder, 2004; Lantz et al., 1998; Winkleby et al., 1992)]. More recent findings reveal a prevailing effect of childhood SES that, at least with respect to certain health outcomes, has a stronger influence than current SES [e.g., (Luo and Waite, 2005)]. Health-related disabilities are commonly associated with low socio-economic status or SES drift. This hypothesis is consistent with reported associations between schizophrenia and low SES, in early studies [e.g., (Dohrenwend et al., 1992; Goldberg and Morrison, 1963; Jones et al., 1993)]. In turn, SES, in and of itself, is associated with increased risk in a variety of domains (physical and mental health, cognitive and socio-emotional development, etc.), consistently over time (Bradley and Corwyn, 2002; Conger and Donnellan, 2007).

The consequences of low SES have been explained in terms of access to capital. Indeed, families from higher SES have easier access to different types of capital (i.e., financial, social, etc.), which, in turn, contribute to more developmentally favorable environments for child development (Hoff-Ginsberg and Tardif, 1995). Low-SES families face more challenges to access these capitals, which increases the risk for subsequent impaired development (Brooks-Gunn and Duncan, 1997). A review suggests that the effects of childhood SES on cognitive development are mediated by the quality of the home environment (Hackman et al., 2010), which can reflect limitations in family resources.

Although both the favorable and detrimental consequences of SES are well documented, less is know about the potential contributors to low maternal SES. In this study, we examined whether maternal childhood adversity taken together with later emotional well-being, more specifically maternal symptoms of prenatal depression, might influence SES, as indicated by income and education. We used a longitudinal birth cohort to examine the effects of both maternal history of early adversity and maternal symptoms of prenatal depression on prenatal SES. We hypothesized that mothers presenting with a history of childhood adversity along with higher levels of prenatal depression would be at increased risk to present with lower income and lower level of education as compared to mothers without these risk factors. We further hypothesized that SES would relate to impaired child behavioural development.

\section{Methods}

\subsection{Participants and procedures}

Our community sample ranged from 230 to 243 mothers, across measures, recruited in Montréal (Québec) and Hamilton (Ontario) at 13-20 weeks gestation from prenatal care clinics at the time of routine ultrasound or through advertisements at hospitals. This group of women (Table 1) constitute a portion of a larger population of mother-child dyads that were part of a longitudinal cohort study (Maternal Adversity, Vulnerability and Neurodevelopment; MAVAN; (O'Donnell et al., 2014)). Eligibility criteria included age 18 or over, singleton gestation, and fluency in French or English and excluded women with severe chronic illness (other than hypertension, asthma, or diabetes) and other serious medical conditions (e.g., placenta previa). Mothers were first assessed during their pregnancy ( $\sim 26$ weeks) and then followed at multiple time points that included both home visits and laboratory sessions. Written, informed consent was obtained from all participants. Ethics approval for all components of the study was obtained. Data were obtained during home-visits during the prenatal period.

\subsection{Measures}

\subsubsection{Maternal history of early adversity}

Maternal history of childhood adversity was assessed using the Childhood Trauma Questionnaire (CTQ; 51) and the Parental Bonding Instrument (PBI; 14). Whereas the CTQ assesses more severe instances of adversity, the PBI captures the subjects' perception of variation in parental experience across the normal range. The CTQ was administered to mothers during a home visit

Table 1

Descriptive statistics for predictors and outcomes.

\begin{tabular}{|c|c|c|c|c|}
\hline \multicolumn{2}{|l|}{ Variable } & Mean & $\begin{array}{l}\text { Standard } \\
\text { deviation }\end{array}$ & $\mathrm{N}$ \\
\hline \multicolumn{2}{|l|}{ Maternal adversity } & -0.09 & 0.89 & - \\
\hline \multicolumn{2}{|l|}{$\begin{array}{l}\text { Maternal prenatal } \\
\text { depression }\end{array}$} & 11.54 & 9.23 & - \\
\hline \multicolumn{2}{|l|}{ Child CBCL score } & 27.57 & 19.40 & \\
\hline \multirow[t]{2}{*}{ Family income - prenatal } & High & - & - & 182 \\
\hline & Low & - & - & 48 \\
\hline \multirow[t]{2}{*}{ Maternal education } & University degree & - & - & 119 \\
\hline & $\begin{array}{l}\text { No University } \\
\text { degree }\end{array}$ & - & - & 124 \\
\hline
\end{tabular}

Note. $\mathrm{CBCL}=$ Child Behavior Checklist. 
both prenatally and when children were aged 24 months. All five subscales (emotional neglect, emotional abuse, physical neglect, physical abuse, and sexual abuse) were used in our analyses. The PBI, which is highly stable over time (Wilhelm et al., 2005), was administered during a home visit when the infants were aged 6 months. Only the maternal care scale of the PBI was entered into the analytical models since it was the subscale scale that related to the construct under study and focused on maternal transmission. We used a previously validated principal component analysis to derive one factor and reduce our measures of maternal childhood adversity (CTQ and PBI) (Bouvette-Turcot et al., 2015; Mileva-Seitz et al., 2011). This factor explained 58\% of the total variance (eigenvalue $=3.51$ ) and was used as an integrated measure of childhood adversity.

\subsubsection{Maternal symptoms of depression}

The depressive state of the mothers was assessed prenatally, at 24-36 weeks of gestation, with the Center for Epidemiologic Studies Depression Scale (CES-D), a self-report, 20-item measure (Radloff, 1997). The CES-D is one of the most common screening tests for depression.

\subsubsection{SES}

Demographic information was obtained prenatally (between 2000 and 2011). We investigated two measures of socioeconomic status: maternal level of education and family income. The "high education" category was comprised of women who had a university degree. Low income was determined using cut-offs for low income category based on the official cut-offs published by Statistics Canada's (http://www.statcan.gc.ca/pub/75f0002m/ 2012002/tbl/tbl02-eng.htm).

\subsubsection{Child behavioural symptoms}

Child emotional symptoms were rated using the Child Behavior CheckList, 1.5-5 year version (CBCL; (Achenbach and Rescorla, 2000)). The CBCL is a 100-item measure that was completed by the mothers when children were aged 5 years. The total symptoms score was retained.

\subsection{Statistical analyses}

Bivariate correlations between all study variables are presented in Table 2. Logistic regressions were performed to predict family income (below cut-off for low income category $=1$; above cutoff $=0$ ) and maternal education (University degree $=1$; no University degree $=0$ ) (Table 3 ). We used the function "GLM" in $R$ (version 3.3.0, 2016-05-03; The R Foundation for Statistical Computing) from the "stats" package (Core Team, 2016). To explore the relevance for prenatal SES on offspring behavioural problems we analyzed income category and maternal education as predictors of

Table 2

Bivariate correlations among all study variables.

\begin{tabular}{|c|c|c|c|c|c|}
\hline & 1. & 2. & 3. & 4. & 5. \\
\hline 1. Maternal adversity & - & $0.33^{* * *}$ & $-.20^{* * *}$ & $0.18^{* * *}$ & $0.15^{*}$ \\
\hline 2. Maternal depression & & - & -.10 & $0.22^{\text {*** }}$ & $0.33^{* * *}$ \\
\hline 3. Maternal education ${ }^{a}$ & & & -.10 & $-.28 * *$ & -.04 \\
\hline 4. Family income $\mathrm{b}^{\mathrm{b}}$ & & & & -.20 & $0.18^{*}$ \\
\hline 5. Child CBCL score & & & & & _- \\
\hline
\end{tabular}

Note. $\mathrm{CBCL}=$ Child Behavior Checklist.

${ }^{\text {a }}$ University degree $=1$; no University degree $=0$.

${ }^{\mathrm{b}}$ Below cut-off for low income $=1$; above cut-off for low income category $=0$, as measured between 2000-2011.

$* p<0.05$.

$* * p<0.01$. total CBCL scores at 5 months using IBM SPSS Statistics (Version 22 ). A $p$-value $<0.05$ was considered as statistically significant.

\section{Results}

Analyses yielded a significant interaction between maternal history of early adversity and maternal symptoms of prenatal depression to predict low family income category as assessed prenatally $\left(O R=1.078 ; p=.002\right.$; model $\left.\chi^{2}(3)=24.432 ; p<0.001\right)$. In the 27 mothers with high levels of both, history of early adversity (score $>$ mean) and clinically relevant symptoms of prenatal depression (score $\geq 16$ ), 15 had an income below the cut-off for low family income category (55.56\%) versus 12 who were above the low-income category (44.44\%). When history of early adversity and symptoms of prenatal depression scores were low $(n=128), 19$ mothers fell below the cut-off for low-income category. In resilient mothers with high adversity but not clinically relevant symptoms of prenatal depression ( $\mathrm{n}=44$ ), 7 fell below the low-income category $(15.91 \%)$. Finally, of the 24 mothers without a history of childhood adversity, who developed clinically relevant symptoms of prenatal depression, 7 fell into the low-income category (22.58\%). Thus, both maternal history of early adversity and maternal symptoms of prenatal depression predicted higher prevalence of low-income category according to Statistics Canada. However, the effects of maternal history of early adversity are much stronger when the mother also suffers from prenatal depression (Fig. 1). This effect remained stable after covarying maternal education as a potential mediator of the association between maternal history of early adversity and income category. Notably, prenatal family income category was highly predictive of family income category at 24 months postpartum $(O R=26.852$; $p<0.001)$ and 36 months $(O R=8.656 ; p<0.001)$.

Furthermore, maternal history of early adversity significantly predicted whether the mothers were holding a university degree or not $(O R=0.860 ; p=.006)$; mothers with a university degree had lower average levels of history of early adversity $(M=-0.274$; $S D=0.607)$ as compared to mothers without a university degree $(M=0.084 ; S D=1.065)$. At the same time, maternal symptoms of prenatal depression did not predict maternal educational attainment $(O R=1.023 ; n s)$. Results did not reveal a significant interaction between maternal history of early adversity and symptoms of prenatal depression on maternal education $(O R=0.998$; $n s)$. Results are displayed in Table 3.

Finally, prenatal family income category $(F(1)=5.136 ; p=.025)$, but not maternal education $(F(1)=0.004 ; n s)$, predicted total problem scores on the Child Behavior CheckList at 5 years postpartum, with children born to low prenatal income families having higher problem scores $(M=35.450 ; S D=22.105)$ compared to those of high income families $(M=25.856 ; S D=18.177)$.

\section{Discussion}

We examined the contributions of both maternal history of early adversity and maternal symptoms of prenatal depression in prediction of (prenatal) SES. Consistent with our hypotheses, our results showed that higher levels of maternal self-reported depressive symptoms moderated the effects of childhood adversity, such that mothers who reported elevated levels of both adversity and depression were more likely to live with disadvantaged SES as indicated by low family income. These interactive effects were obtained over and above the main effects of maternal history of early adversity. Low prenatal family income seems highly relevant as an environmental factor a child grows up in, since family income even at this early time point was highly predictive of later 
Table 3

Regressing maternal history of early adversity and maternal prenatal depression onto low prenatal family income category (cut-off based on Statistics Canada for low income category) and maternal education (University degree).

\begin{tabular}{|c|c|c|c|c|c|c|c|c|}
\hline & \multirow[t]{2}{*}{ B } & \multirow[t]{2}{*}{ SE } & \multicolumn{3}{|c|}{ 95\% Confidence Interval for OR } & \multirow[t]{2}{*}{$\mathrm{p}$} & \multirow[t]{2}{*}{$\mathrm{R}^{2}($ Cox \& Snell $)$} & \multirow[t]{2}{*}{ Nagelkerke } \\
\hline & & & Lower Bound & Odds Ratio & Upper Bound & & & \\
\hline \multicolumn{7}{|c|}{ Family income category $^{\mathrm{a}}$} & \multirow[t]{5}{*}{0.101} & \multirow[t]{5}{*}{0.157} \\
\hline constant & 2.131 & 0.325 & & & & $<0.001$ & & \\
\hline Adversity Score & -0.908 & 0.447 & 0.156 & 0.403 & 0.915 & 0.043 & & \\
\hline CES-D prenatal & 0.043 & 0.019 & 1.005 & 1.044 & 1.085 & 0.026 & & \\
\hline Interaction term & 0.075 & 0.025 & 1.030 & 1.078 & 1.136 & 0.002 & & \\
\hline \multicolumn{6}{|c|}{ Maternal University education ${ }^{\mathrm{b}}$} & & \multirow[t]{4}{*}{0.043} & \multirow[t]{4}{*}{0.057} \\
\hline constant & -0.018 & 0.225 & & & & 0.937 & & \\
\hline Adversity Score & -0.481 & 0.177 & 0.429 & 0.860 & 0.618 & 0.006 & & \\
\hline CES-D prenatal & -0.007 & 0.015 & 0.964 & 1.023 & 0.993 & 0.646 & & \\
\hline
\end{tabular}

Note. All data were collected when mothers were between 24 and 36 weeks of gestation. B = regression coefficient. CES-D=Center for Epidemiologic Studies Depression Scale $\mathrm{SE}=$ Standard error. $\mathrm{OR}=$ Odds ratio.

a Below cut-off for low income=1; above cut-off for low income category=0 as measured between 2000 and 2011.

${ }^{\mathrm{b}}$ University degree $=1$; no University degree $=0$.

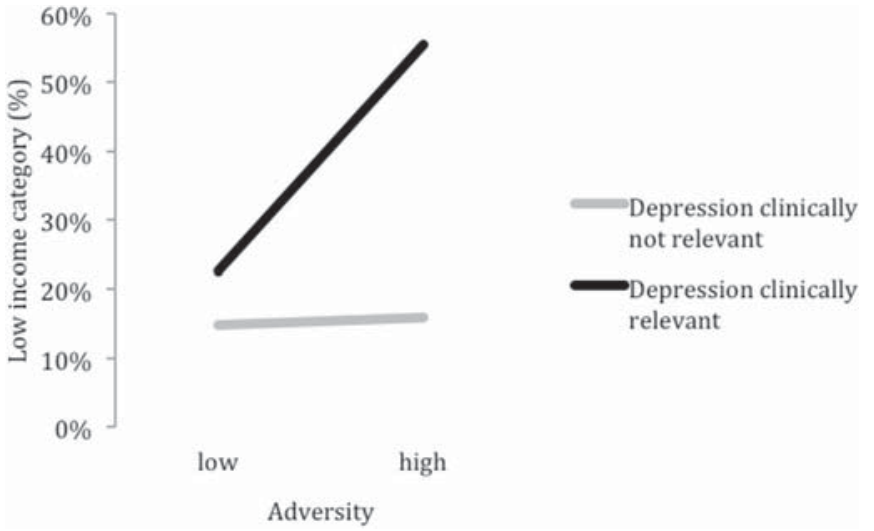

Fig. 1. Interactive effects of maternal history of early adversity and maternal symptoms of prenatal depression on prenatal income category.

family income as well as child behavioural problems at 5 years postpartum. With regards to maternal education, only a main effect of maternal history of early adversity was obtained, which suggests that mothers with a history of childhood adversity are less likely to complete university.

These preliminary findings are consistent with those of previous studies associating psychopathology with lower SES [e.g., (Jones et al., 1993)]. Our findings confirm the importance of the multifaceted operation of risk factors leading to poorer environmental conditions. Indeed, whereas detrimental consequences of growing up with low SES are widely studied [e.g., (Conger and Donnellan, 2007)], circumstances enhancing the likelihood of living with low SES are largely understudied.

Parental SES defines that of the child. It is increasingly apparent that childhood SES, operating independently of adult SES, influences developmental outcomes with effects sustained in adulthood (Luo and Waite, 2005; Bradley and Corwyn, 2002; Conger and Donnellan, 2007; Brooks-Gunn and Duncan, 1997; Hackman et al., 2010; Lam et al., 2012; McLoyd, 1998; Miller et al., 2009). Thus, our findings are also interesting to consider in the context of intergenerational risk transmission paradigms that suggest that maternal history of early adversity may affect the environment that shapes the health of the next generation (Plant et al., 2013; Bouvette-Turcot et al., 2015; Collishaw et al., 2004), thus contributing to an intergenerational transmission pathway. As such, our results may provide preliminary evidence for social drift, in emphasizing adverse conditions (i.e., the interactive effects of both maternal history of early adversity and maternal symptoms of prenatal depression) that may jeopardize socioeconomic conditions and potential improvements.

This study also emphasizes the moderating role of maternal symptoms of prenatal depression. Family SES appeared to be negatively affected by a maternal history of early adversity but only for mothers who presented with higher symptoms of prenatal depression. Contrastingly, lower levels of maternal prenatal depressive symptoms seemed to be rather protective with regards to SES. One may then hypothetically consider both maternal history of early adversity and maternal symptoms of prenatal depression as cumulative risk factors increasing the risk of living in low SES that may then extend to suboptimal child outcomes.

Our preliminary findings also underscore the importance of prevention and community support. Successful intervention could potentially disrupt the intergenerational pathway that links childhood adversity, depression, SES and developmental outcomes in the offspring. Maternal depression has already been identified as a moderator in intervention studies targeting children. Mediational analyses also reveal that maternal depression mediated internalizing and externalizing symptom reduction in children following interventions (Shaw et al., 2009).

It is important to note that this study was conducted with a community sample. Few mothers in this sample experienced severe trauma or reached criteria for clinical depression. Nevertheless, despite the relatively moderate level of risk, we were able to reveal a statistically significant effect on maternal SES. Moreover, recent studies from community samples show that self-reported depressive symptoms across the normal range predict variation in cortico-limbic brain structures in neonates (Qiu et al., 2015; Rifkin-Graboi et al., 2013). These findings underscore the importance of maternal emotional well-being across the population. Our results underscore the potential for familial risk transmission within inter-individual normative variations for early life adversity, prenatal depression levels, and SES. One weakness to the current approach is that both maternal history of early adversity and prenatal depression were assessed with self-report measures. However, all instruments are widely used, share good psychometric properties and good validity (Bernstein et al., 1994; Wilhelm et al., 2005; Radloff, 1997). Furthermore, family income supposedly assesses income of the mother and her partner, which might entangle our findings to some degree. We also had to combine the categories for maternal education, since the groups with lower levels of education would have been too small. Notably, the proportion of variance in maternal education explained by 
maternal history of early adversity was small, indicating other factors might be at play. Research should thus also examine years of education or examine the current research question in a sample with lower levels of education and explore other potential intervening factors. Nevertheless, we speculate that the effects of childhood adversity and symptoms of depression would be even greater in high-risk samples.

Notwithstanding these limitations, this study is one of the first to consider SES as an outcome and to examine its longitudinal precursors. More research is needed to better understand conditions leading to low SES, transmission, maintenance, or drift. As such, future research should attempt to assess early life SES to further document intergenerational risk onset and continuity. Maternal history of childhood maltreatment is also associated with increased risk for offspring antisocial behavior (Plant et al., 2015; Pawlby et al., 2011). Path analysis (Pawlby et al., 2011) reveals that offspring experience of child maltreatment mediated the association between exposure to maternal depression in pregnancy and offspring psychopathology. Given those associations, path analyses integrating SES to those risk factors should be explored. Future models should also encompass cumulative risk factors integrating genetic markers and investigate offspring development within those conditions.

\section{References}

Achenbach, T.M., Rescorla L.A., 2000. Manual for the ASEBA preschool forms and profiles. University of Vermont Department of Psychiatry.

Backlund, E., Sorlie, P.D., Johnson, N.J., 1996. The shape of the relationship between income and mortality in the United States: evidence from the National Longitudinal Mortality Study. Ann. Epidemiol. 6, 12-20.

Berlin, L.J., Appleyard, K., Dodge, K.A., 2011. Intergenerational continuity in child maltreatment: mediating mechanisms and implications for prevention. Child Dev. 82, 162-176.

Bernstein, D.P., Fink, L., Handelsman, L., Foote, J., Lovejoy, M., Wenzel, K., et al., 1994 Initial reliability and validity of a new retrospective measure of child abuse and neglect. Am. J. Psychiatry 151, 1132-1136.

Bifulco, A., Moran, P.M., Ball, C., Jacobs, C., Baines, R., Bunn, A., et al., 2002. Childhood adversity, parental vulnerability and disorder: examining inter-generational transmission of risk. J. Child Psychol. Psychiatry 43, 1075-1086.

Bouvette-Turcot, A.-A., Fleming, A.S., Wazana, A., Sokolowski, M.B., Gaudreau, H., Gonzalez, A., et al., 2015. Maternal childhood adversity and child temperament: an association moderated by child 5-HTTLPR genotype. Genes Brain Behav. 14 229-237.

Bradley, R.H., Corwyn, R.F., 2002. Socioeconomic status and child development. Annu Rev. Psychol. 53, 371-399.

Brooks-Gunn, J., Duncan, G.J., 1997. The effects of poverty on children. Future Child 7, 55-71.

Brown, A.M., Whiteside, S.P., 2008. Relations among perceived parental rearing behaviors, attachment style, and worry in anxious children. J. Anxiety Disord. 22, 263-272.

Brown, G.W., Moran, P., 1994. Clinical and psychosocial origins of chronic depressive episodes. I: a community survey. Br. J. Psychiatry 165, 447-456.

Burt, K.B., Van Dulmen, M.H., Carlivati, J., Egeland, B., Sroufe, L.A., Forman, D.R., et al Mediating links between maternal depression and offspring psychopathology: The importance of independent data. J. Child Psychol. Psychiatry. Vol 46, pp. 490-499.

Caspi, A., Sugden, K., Moffitt, T.E., Taylor, A., Craig, I.W., Harrington, H., et al., 2003. Influence of life stress on depression: Moderation by a polymorphism in the 5-HTT gene. Science 301, 386-389.

Cicchetti, D., Toth, S.L., 1995. Developmental psychopathology and disorders of affect. In: Cicchetti, D., Cohen, D.J. (Eds.), Dev Psychopathol. John Wiley \& Sons, Oxford, pp. 369-420.

Collishaw, S., Maughan, B., Goodman, R., Pickles, A., 2004. Time trends in adolescent mental health. J. Child Psychol. Psychiatry 45, 1350-62.

Collishaw, S., Dunn, J., O'Connor, T.G., Golding, J., 2007. Maternal childhood abuse and offspring adjustment over time. Dev. Psychopathol. 19, 367-383.

Conger, R.D., Donnellan, M.B., 2007. An interactionist perspective on the socioeconomic context of human development. Annu Rev. Psychol. 58, 175-199. Dohrenwend, B.P. Levav, I, Shrout, P.E, Schwartz, S, Naveh, G, Link, B.G, et al. 1992. Socioeconomic status and psychiatric disorders: the causation-selection issue. Science 255, 946-952.

Fergusson, D.M., Boden, J.M., Horwood, L.J., 2008. Exposure to childhood sexual and physical abuse and adjustment in early adulthood. Child Abus. Negl. 32, 607-619.

Galambos, N.L., Barker, E.T., Almeida, D.M., 2003. Parents do matter: Trajectories of change in externalizing and internalizing problems in early adolescence. Child Dev. 74, 578-594.

Goldberg, E.M., Morrison, S.L., 1963. Schizophrenia and social class. Br. J. Psychiatry 109, 785-802.

Goodman, S.H., Rouse, M.H., Connell, A.M., Broth, M.R., Hall, C.M., Heyward, D., 2011. Maternal depression and child psychopathology: a meta-analytic review. Clin. Child Fam. Psych. 14, 1-27.

Hackman, D.A., Farah, M.J., Meaney, M.J., 2010. Socioeconomic status and the brain: mechanistic insights from human and animal research. Nat. Rev. Neurosci. 11, 651-659.

Hale, W.W., Engels, R., Meeus, W., 2006. Adolescent's perceptions of parenting behaviours and its relationship to adolescent Generalized Anxiety Disorder symptoms. J. Adolesc. 29, 407-417.

Hane, A.A., Fox, N.A., 2006. Ordinary variations in maternal caregiving influence human infants' stress reactivity. Psychol. Sci. 17, 550-556.

Heim, C., Nemeroff, C.B., 2001. The role of childhood trauma in the neurobiology of mood and anxiety disorders: Preclinical and clinical studies. Biol. Psychiatry 49, 1023-1039.

Hill, J., Pickles, A., Burnside, E., Byatt, M., Rollinson, L., Davis, R., et al., 2001. Child sexual abuse, poor parental care and adult depression: Evidence for different mechanisms. Br. J. Psychiatry 179, 104-109.

Hoff-Ginsberg, E., Tardif, T. 1995. Socioeconomic status and parenting. Handbook of parenting, Vol 2: Biology and ecology of parenting. Hillsdale, NJ, England: Lawrence Erlbaum Associates, Inc. pp. 161-188.

Isaacs, S.L., Schroeder, S.A., 2004. Class-the ignored determinant of the nation's health. N Engl. J. Med. 351, 1137-1142.

Jones, P.B., Bebbington, P., Foerster, A., Lewis, S.W., Murray, R.M., Russell, A., et al, 1993. Premorbid social underachievement in schizophrenia. Results from the Camberwell Collaborative Psychosis Study. Br. J. Psychiatry 162, 65-71.

Kessler, R.C., 1997. The effects of stressful life events on depression. Ann. Rev. Psychol. 48, 191.

Kessler, R.C. 2006. The epidemiology of depression among women. Women and depression: A Handbook for the Social, Behavioral, and Biomedical Sciences, pp. 22-37.

Kiernan, K.E., Huerta, M.C., 2008. Economic deprivation, maternal depression, parenting and children's cognitive and emotional development in early childhood. Br. J. Sociol. 59, 783-806.

Lam, L.L., Emberly, E., Fraser, H.B., Neumann, S.M., Chen, E., Miller, G.E., et al., 2012 Factors underlying variable DNA methylation in a human community cohort. Proc. Natl. Acad. Sci. USA 109, 17253-17260.

Lansford, JE, Dodge, K.A. Pettit, G.S., Bates, J.E., Crozier, J. Kaplow, J.A, 2002. 12 year prospective study of the long-term effects of early child physical maltreatment on psychological, behavioral, and academic problems in adolescence. Arch. Pedia. Adolesc. Med. 156, 824-830.

Lantz, P.M., House, J.S., Lepkowski, J.M., Williams, D.R., Mero, R.P., Chen, J., 1998. Socioeconomic factors, health behaviors, and mortality: results from a nationally representative prospective study of us adults. JAMA 279, 1703-1708.

Lieb, R., Wittchen, H.U., Hofler, M., Fuetsch, M., Stein, M.B., Merikangas, K.R., 2000 Parental psychopathology, parenting styles, and the risk of social phobia in offspring - A prospective-longitudinal community study. Arch. Gen. Psychiatry 57, 859-866.

Luo, Y., Waite, L.J., 2005. The impact of childhood and adult SES on physical, mental, and cognitive well-being in later life. J. Gerontol. Ser. B: Psychol. Sci. Soc. Sci. 60 S93-S101.

McLoyd, V.C., 1998. Socioeconomic disadvantage and child development. Am. Psychol. 53, 185-204.

Mileva-Seitz, V., Kennedy, J., Atkinson, L., Steiner, M., Levitan, R., Matthews, S.G., et al., 2011. Serotonin transporter allelic variation in mothers predicts maternal sensitivity, behavior and attitudes toward 6-month-old infants. Genes Brain Behav. 10, 325-333.

Miller, G.E., Chen, E., Fok, A.K., Walker, H., Lim, A., Nicholls, E.F., et al., 2009. Low early-life social class leaves a biological residue manifested by decreased glucocorticoid and increased proinflammatory signaling. Proc. Natl. Acad. Sci. USA 106, 14716-14721.

Nanni, V., Uher, R., Danese, A., 2012. Childhood maltreatment predicts unfavorable course of illness and treatment outcome in depression: a meta-analysis. Am. J. Psychiatry 169, 141-151.

O'Donnell, K.A., Gaudreau, H., Colalillo, S., Steiner, M., Atkinson, L., Moss, E., et al. 2014. The maternal adversity, vulnerability and neurodevelopment project: theory and methodology. Can. J. Psychiatry 59, 497-508.

Parker, G., Tupling, H., Brown, L.B.A., 1979. Parental bonding instrument. Br. J. Med Psychol. 52, 1-10.

Pawlby, S., Hay, D., Sharp, D. Waters, C.S, Pariante, C.M., 2011. Prenatal depression and offspring psychopathology: the influence of childhood maltreatment. Br. J. Psychiatry, $1-7$

Plant, D.T., Pariante, C.M., Sharp, D., Pawlby, S., 2015. Maternal depression during pregnancy and offspring depression in adulthood: role of child maltreatment. Br. J. Psychiatry 207, 213-220. 
Plant, D.T., Barker, E.D., Waters, C.S., Pawlby, S., Pariante, C.M., 2013. Intergenerational transmission of maltreatment and psychopathology: The role of prenatal depression. Psychol. Med. 43, 519-528.

Qiu, A., Anh, T.T., Li, Y., Chen, H., Rifkin-Graboi, A., Broekman, B.F.P., et al., 2015. Prenatal maternal depression alters amygdala functional connectivity in 6-month-old infants. Transl. Psychiatry 5, e508.

R Core Team. 2016. R: A language and environment for statistical computing. R Foundation for Statistical Computing, Vienna, Austria. Url : 〈https://www.Rproject.org $/\rangle$.

Radloff, L.S., 1997. The CES-D Scale: a self-report depression scale for research in the general population. Appl Psychol. Meas. 1, 385-401.

Rifkin-Graboi, A., Bai, J., Chen, H., Hameed, W.B., Sim, L.W., Tint, M.T. et al., 2013. Prenatal maternal depression associates with microstructure of right amygdala in neonates at birth. Biol. Psychiatry 74, 837-844.

Rubin, K.H., Both, L., Zahn-Waxler, C., Cummings, E.M., Wilkinson, M., 1991. The dyadic play behaviors of preschoolers with depressed versus well mothers. Dev. Psychopathol. 3, 243-251.

Shanahan, L., Copeland, W., Costello, E.J., Angold, A., 2008. Specificity of putative psychosocial risk factors for psychiatric disorders in children and adolescents. J. Child Psychol. Psychiatry 49, 34-42.

Shaw, D.S., Connell, A., Dishion, T.J., Wilson, M.N., Gardner, F., 2009. Improvements in maternal depression as a mediator of intervention effects on early childhood problem behavior. Dev. Psychopathol. 21, 417-439.

Tanskanen, A., Hintikka, J., Honkalampi, K., Haatainen, K., Koivumaa-Honkanen, H., Viinamaki, H., 2004. Impact of multiple traumatic experiences on the persistence of depressive symptoms-a population-based study. Nord J. Psychiatry 58, 459-464.

Thornberry, T.P., Ireland, T.O., Smith, C.A., 2001. The importance of timing: the varying impact of childhood and adolescent maltreatment on multiple problem outcomes. Dev. Psychopathol. 13, 957-979.
Trickett, P.K., Noll, J.G., Reiffman, A., Putnam, F.W., 2001. Variants of intrafamilial sexual abuse experience: Implications for short- and long-term development. Dev. Psychopathol. 13, 1001-1019.

Van Brakel, A.M.L., Muris, P., Bogels, S.M., Thomassen, C.A., 2006. Multifactorial model for the etiology of anxiety in non-clinical adolescents: main and interactive effects of behavioral inhibition, attachment, and parental rearing. J. Child Fam. Stud. 15, 569-579.

Weissman, M.M., Wickramaratne, P., Nomura, Y., Warner, V., Verdeli, H., Pilowsky, D.J., et al., 2005. Families at high and low risk for depression - a3-generation study. Arch. Gen. Psychiatry 62, 29-36.

Weissman, M.M., Wickramaratne, P., Nomura, Y., Warner, V., Pilowsky, D., Verdeli, H., 2006. Offspring of depressed parents: 20 years later. Am. J. Psychiatry 163 , 1001-1008.

Wickramaratne, P., Gameroff, M.J., Pilowsky, D.J., Hughes, C.W., Garber, J., Malloy, E., et al., 2011. Children of depressed mothers 1 year after remission of maternal depression: findings from the STAR*D-Child study. Am. J. Psychiatry 168 593-602.

Widom, C.S., DuMont, K., Czaja, S.J., 2007. A prospective investigation of major depressive disorder and comorbidity in abused and neglected children grown up. Arch. Gen. Psychiatry 64, 49-56.

Wilhelm, K., Niven, H., Parker, G., Hadzi-Pavlovic, D., 2005. The stability of the Parental Bonding Instrument over a 20-year period. Psychol. Med. 35, 387-393.

Winkleby, M.A., Jatulis, D.E., Frank, E., Fortmann, S.P., 1992. Socioeconomic status and health: How education, income, and occupation contribute to risk factors for cardiovascular disease. Am. J. Public Health 82, 816-820.

Zlotnick, C., Mattia, J., Zimmerman, M., 2001. Clinical features of survivors of sexual abuse with major depression. Child Abus. Negl. 25, 357-367.

Zlotnick, C., Warshaw, M., Shea, M.T., Keller, M.B., 1997. Trauma and chronic depression among patients with anxiety disorders. J. Consult Clin. Psychol. 65, 333-336. 